\title{
Patrimonio arqueológico y comunidad: confluencias y problemáticas en el sitio Vuelta de Obligado (Argentina)
}

Odlanyer Hernández de Lara | Facultad de Filosofía y Letras, Universidad de Buenos Aires

Ana Paula Motta | Facultad de Filosofía y Letras, Universidad de Buenos Aires

Milva Ximena Umaño | Facultad de Filosofía y Letras, Universidad de Buenos Aires

URL de la contribución <www.iaph.es/revistaph/index.php/revistaph/article/view/3362>

\section{RESUMEN}

El objetivo de este trabajo es realizar una caracterización del patrimonio cultural y natural del sitio arqueológico Vuelta de Obligado, ubicado en la provincia de Buenos Aires (Argentina), así como analizar las problemáticas de conservación y proponer alternativas de desarrollo, teniendo en cuenta las investigaciones arqueológicas.

En esta localidad se desarrolló una de las batallas de la guerra del Paraná y todavía pueden verse huellas de su presencia. Se pueden distinguir diversas dificultades de conservación del patrimonio tanto natural como cultural de este sitio. Entre las primeras, la creación de un espacio protegido ha contribuido a la conservación de un pequeño parche de vegetación. Sin embargo, la delimitación de esta área protegida no es lo suficientemente representativa. Entre las segundas, encontramos el accionar del hombre y el desarrollo urbano como principal causa de deterioro, lo que implica diversos grados de conservación del patrimonio. Se proponen algunas estrategias de abordaje de estas circunstancias para contribuir a la valorización del espacio, con vistas a profundizar el interés por el desarrollo de la localidad, no solamente por el público, sino también desde lo institucional.

\section{Palabras clave}

Argentina | Conservación | Historia | Patrimonio cultural | Patrimonio natural | Planificación | Sitio Arqueológico Vuelta de Obligado (San Pedro, Buenos Aires, Argentina) | 


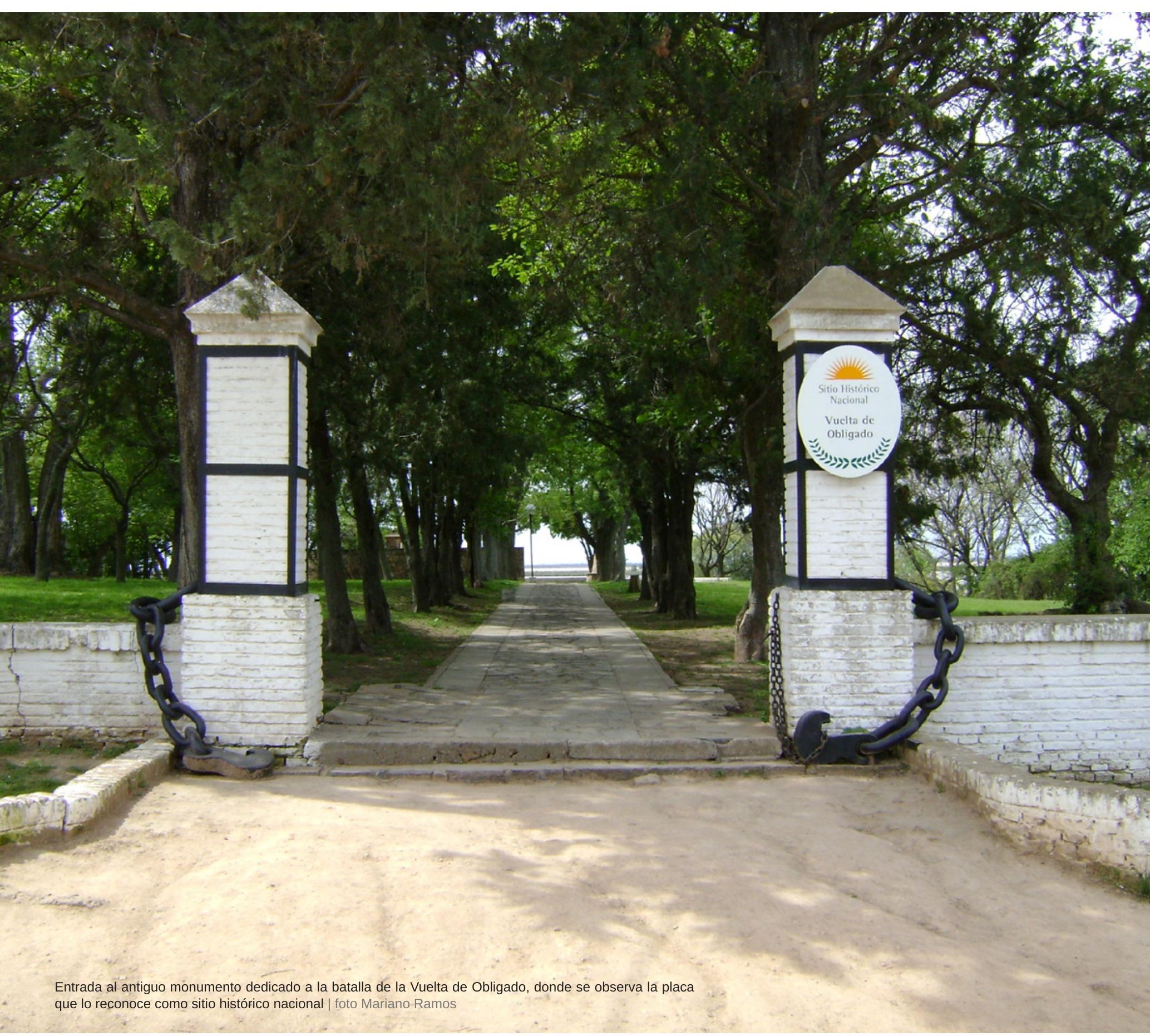




\section{INTRODUCCIÓN}

La localidad de Vuelta de Obligado, en las márgenes del río Paraná (Argentina), es un espacio donde la riqueza natural de la flora y la fauna se combinan con una historia de lucha por la soberanía argentina que trasciende la centuria decimonónica para arraigarse en el espíritu de las poblaciones actuales que han habitado este paraje durante generaciones. Las barrancas del Paraná contribuyeron a que este lugar fuera elegido para establecer las defensas de las tropas argentinas durante la batalla de Vuelta de Obligado (1845), donde en la actualidad se conservan evidencias arqueológicas de los parapetos utilizados durante la batalla.

Por otra parte, el vínculo de la comunidad de pescadores asentados en el paraje con el espacio natural a través del tiempo ha creado un sentido de pertenencia que ha fortalecido la identidad cultural y la trasmisión de un relato oral que se remonta a tiempos de la guerra del Paraná. De la mano de estas personas comenzó a rescatarse la historia del lugar, a través de las evidencias materiales que fueron encontrando y resguardando en sus hogares hasta la creación de un museo donde se mostraran no solamente los objetos, sino también se contaran los hechos y se rescataran los valores del comienzo de una tradición nacional.

La significación histórica del paraje de Vuelta de Obligado, así como su riqueza natural, conllevó a que el Senado y la Cámara de Diputados de la provincia de Buenos Aires promulgaran varias ordenanzas sobre este espacio que culminaron con la declaración del lugar como reserva y monumento natural, lo que contribuyó, en alguna manera, a su conservación.

Si bien la conservación de espacios naturales en Argentina tiene un derrotero bastante amplio, especialmente en lo que afecta a los parques nacionales y a algunas provincias con un desarrollo institucional significativo, para el caso de las reservas a escala municipal, estas dependen en gran medida de los impulsos locales. En este sentido, el área de Vuelta de Obligado, que hasta el momento se limita al ámbito municipal, se ve afectada por la poca operatividad gubernamental y la capacidad de planificación, incapaz de aplicar los lineamientos provinciales, que cuentan con un sistema provincial de áreas naturales protegidas con la potencialidad necesaria para su mejor puesta en valor y manejo de los recursos, tanto naturales como culturales.

En esta ocasión, presentamos una caracterización del paisaje teniendo en cuenta los recursos culturales y naturales, poniendo especial énfasis en los principales componente que afectan a la conservación del paraje Vuelta de Obligado. Además, se analizan los problemas detectados y se proponen soluciones para su mejor desarrollo, teniendo en cuenta el uso del espacio por el público y la necesidad de una interacción con la arqueología de la localidad y su conservación. 


\section{EL ENTORNO NATURAL}

El paisaje cultural Vuelta de Obligado se encuentra en el partido de San Pedro, al norte de la provincia de Buenos Aires. El área dista aproximadamente $17 \mathrm{~km}$ de la ciudad de San Pedro, abarcando una superficie total de 40 hectáreas, donde se incluye el área núcleo y de amortiguación.

El ambiente natural donde está enclavada la zona de interés posee una riqueza y diversidad de flora y fauna de gran valor, gracias al entorno embellecido por las aguas del río Paraná y los fértiles suelos, ricos en materiales orgánicos. Los ríos y arroyos se extienden a lo largo de unos 100 kilómetros, lo que contribuye a la acumulación de sedimentos acarreados por el sistema fluvial del Paraná-Paraguay, que influye en la cambiante formación de islas y bancos de arena. Uno de los aspectos más significativos de la ribera del río lo constituyen las barrancas, con una importante impregnación calcárea (tosca) y un desnivel que ronda entre los 15 y 20 metros.

En el área se destaca la presencia de un bosque nativo de tala (Celtis tala) que ofrece refugio a una importante variedad de plantas y animales, característicos del monte norteño. Además, unas 250 especies de aves, entre las que se encuentran algunas permanentes y otras transitorias, enriquecen el entorno natural de la zona.

\section{VUELTA DE OBLIGADO}

La reserva y monumento natural Vuelta de Obligado se conforma como un parque histórico-natural que está regulado por la legislación municipal y provincial $^{1}$. La creación de un museo local en su interior ha contribuido no solamente a que funcione como referente para el conocimiento de la historia local, sino también como punto de información para el propio sitio de Vuelta de Obligado, controlando el único acceso desde la calle.

Su constitución paulatina ha incidido en su tratamiento ontológico, lo que ha implicado la carencia de un plan director que regule y coordine la planificación general del espacio, con los consecuentes planes específicos de manejo de recursos.

\section{Antecedentes}

En abril de 1997 el Senado y la Cámara de Diputados de la provincia de Buenos Aires promulgan la ley 11.955 , cuando declaran de interés provincial el Proyecto de Reconstrucción Histórica de la Vuelta de Obligado, sentando el primer antecedente donde se deja consignado el interés de las autoridades de la provincia por el lugar. 
Localización del área de Vuelta de Obligado, partido de San Pedro, provincia de Buenos Aires

A la par, dos grupos de investigación presentan proyectos con el objetivo de abordar el estudio desde el punto de vista arqueológico del sitio histórico donde tuvo lugar la batalla, aunque sólo uno continuó las labores. En 1998 se presenta el proyecto del Programa de Arqueología Histórica y Estudios Pluridisciplinarios de la Universidad Nacional de Luján, dirigido por el Dr. Mariano Ramos, que comienza a realizar las primeras labores en el año 2000.

A lo largo de más de diez años continuaron desarrollándose los trabajos, excavándose en dos de las cuatro baterías que se establecieron en el lugar, especialmente en la denominada General Brown, donde se localizaron varias huellas de postes e improntas de maderas que se han interpretado como el basamento (cureñas) de las piezas de artillería. El hallazgo de fragmentos de proyectiles explosivos utilizados por la armada anglo-francesa, acompañados de maderas con huellas de combustión y metales derretidos, muestra parte de los estragos que ocasionaron en las baterías argentinas, cuestión que se apoya en la documentación histórica disponible del lugar, donde se hace referencia a la gran cantidad de bajas en las tropas locales (RAMOS; BOGNANNI; LANZA et ál., 2011).

Otro de los espacios trabajados refiere a la ubicación del campamento donde se establecieron aproximadamente 2000 soldados durante tres meses antes de la batalla, para la preparación de las defensas. Dentro del bosque de árboles nativos que aún se conserva en el lugar, es donde parece haber | plano Odlanyer Hernández de Lara

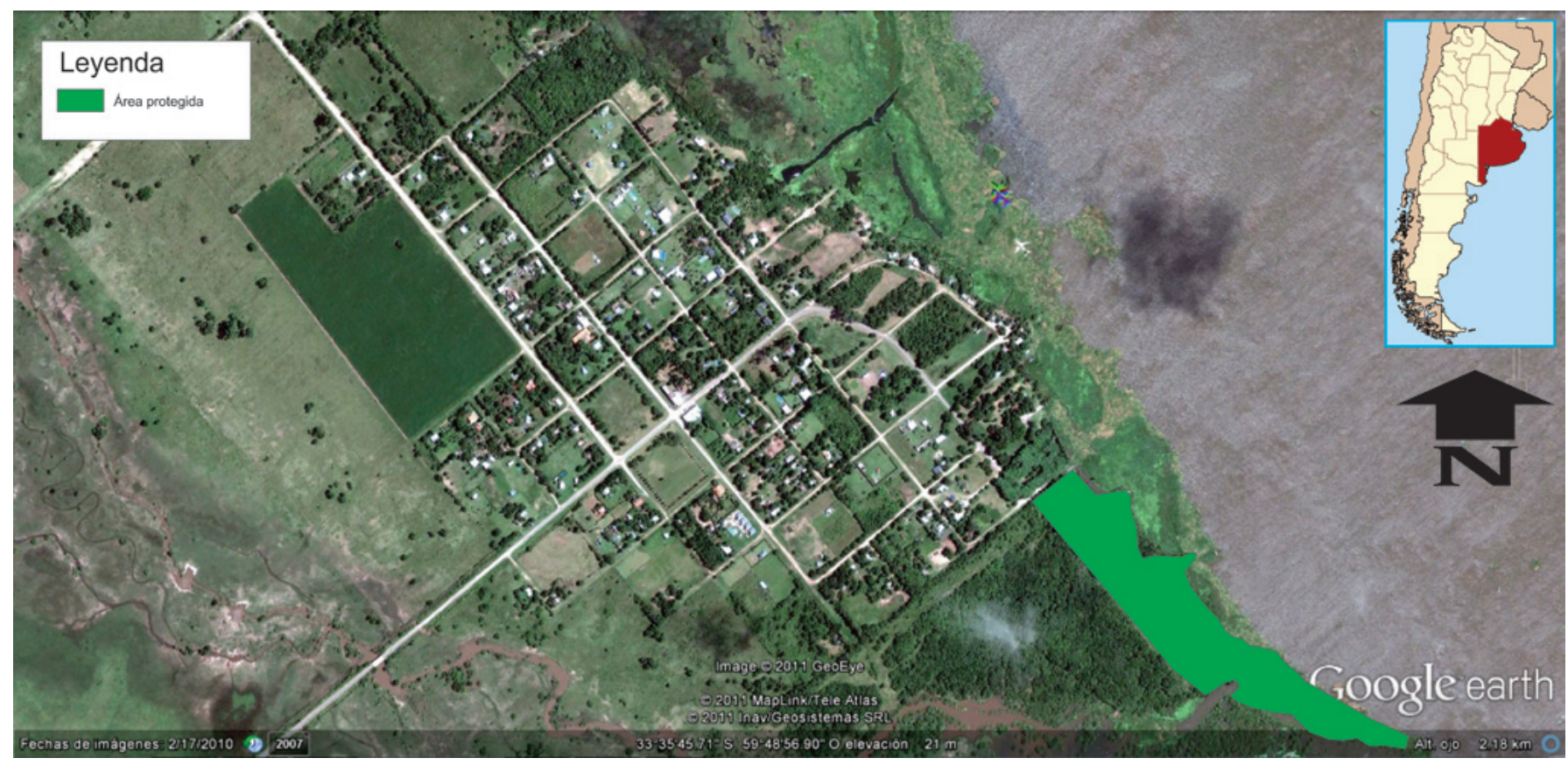


estado el campamento, lo que ha implicado la realización de una serie de sondeos y exploraciones superficiales que han aportado algunas evidencias asociadas al momento de la batalla (LANZA; HERNÁNDEZ DE LARA; BOGNANNI et ál., 2011).

Éste es uno de los espacios que más ha sido afectado por acciones vandálicas con uso de detectores de metales, donde en varias ocasiones han quedado pozos con restos de materiales cerámicos y vítreos fragmentados. Para diciembre del año 2000, la ordenanza 5184 establecía una zona de reserva natural, en la que debía conservarse el ecosistema. Además, se establece la parcela 1031 como un refugio histórico natural, prohibiéndose la subdivisión y el cambio de uso del predio.

En enero de 2003, la ley 13.004 modifica a la anterior de 1997 (ley 11.955), tomando una dimensión más significativa, que no se limita solamente a la reconstrucción histórica, sino que implica la instalación de un museo que conmemore el sitio del combate, a la vez que se declara el lugar como reserva y monumento natural.

Un aspecto que merece especial atención está relacionado con la invitación que se realiza a los municipios del noroeste de la provincia de Buenos Aires para que participen en el proyecto y que contribuyan al "enriquecimiento cultural del hecho histórico". De este modo, se propone generar un eje turísticonatural de relevada trascendencia para la región.
Ampliación del área de amortiguamiento, teniendo en cuenta los recursos arqueológicos del área | plano Odlanyer Hernández de Lara

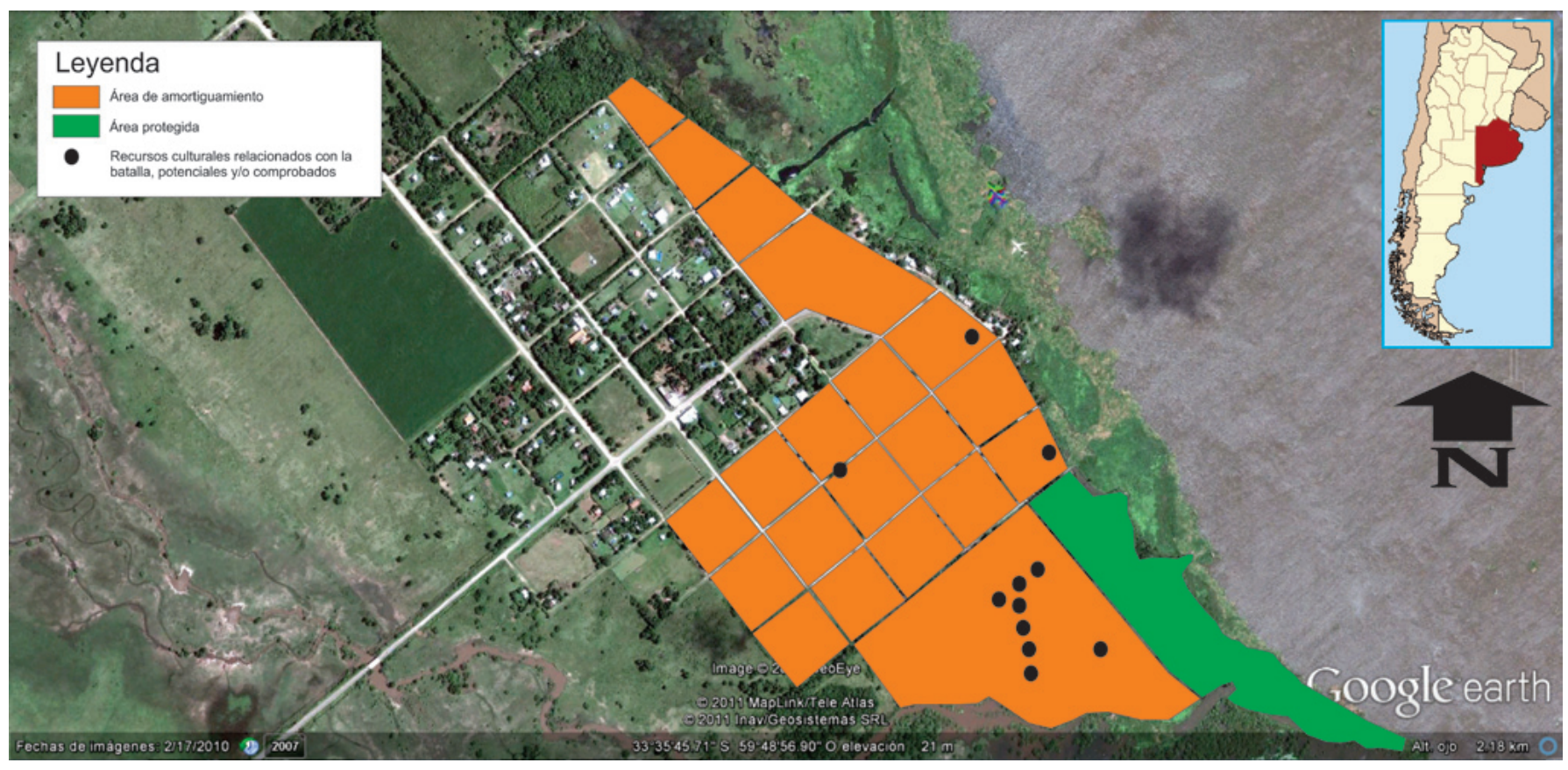


Plano de zonificación de la propuesta de plan de manejo anterior | fuente BODRATI et ál., 2005

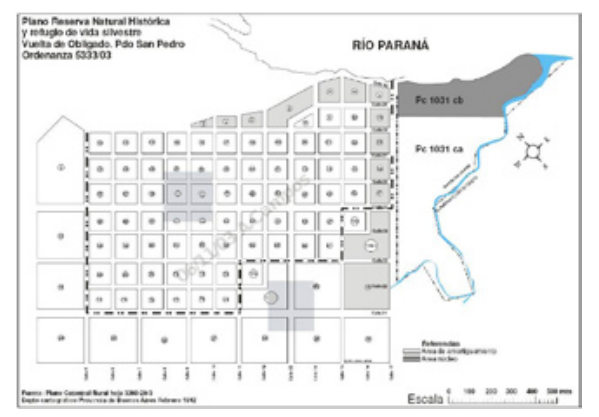

En junio del mismo año, la ordenanza 5333 establece un ordenamiento más apropiado del terreno con vistas a su conservación, designando un área núcleo - de mayor protección-y un área de amortiguación, que implica terrenos municipales y privados, con la finalidad de guardar la integridad del área núcleo.

Esta ordenanza determina además las acciones que estarán prohibidas dentro de la reserva, la implementación de un plan de manejo, dotar de personal capacitado y la señalización con cartelería informativa y normativa. Además, establece los procedimientos para controlar las modificaciones que puedan llegar a afectar la conservación de la reserva, para lo cual se exige la realización de un estudio de impacto ambiental.

Como se ha podido observar, diversas acciones y actos administrativos por parte del gobierno local y provincial a lo largo de seis años culminaron con la creación del área protegida denominada parque histórico natural Vuelta de Obligado donde, desde el inicio, se resaltaron tanto los valores históricos como naturales del paraje.

Otro tema de importancia corresponde a la elaboración de una propuesta de plan de manejo precedente por parte de un equipo de trabajo de Aves Argentinas/Asociación Ornitológica del Plata (BODRATI; BODRATI; CUENCA et ál., 2005) donde se plantean algunos problemas que ya han sido resueltos y otros que aún mantienen vigencia. La existencia de este plan ha sido mencionada en varias ordenanzas, aunque se refiere la no aplicación del mismo, al menos no en todo su alcance. Un aspecto señalable es que el mayor énfasis del plan se orienta hacia los recursos naturales, casi sin hacer referencia a la protección y valor de los culturales, aunque son mencionados.

La mayor significación lo constituye sin dudas su propia existencia, aunque no haya sido aplicado como corresponde. En la actualidad se hace imprescindible no solamente su actualización, sino -más importante aún- que su aplicación se haga efectiva en todos sus aspectos y que se mantenga un constante seguimiento.

\section{La situación actual del patrimonio cultural}

En la reserva están presentes al menos un sitio arqueológico precolombino y el sitio de la batalla. El primero de estos fue descubierto muy recientemente de forma fortuita, como consecuencia de la construcción de un baño dentro del área protegida, muy cerca del museo. Hasta el momento, las evidencias que aparecieron, como fragmentos de cerámicas y restos faunísticos, han permitido confirmar la significación del contexto arqueológico. Esto conllevó a la organización de un proyecto de investigación para el estudio pormenorizado del lugar desde el punto de vista arqueológico (DLAPA, 2011). 


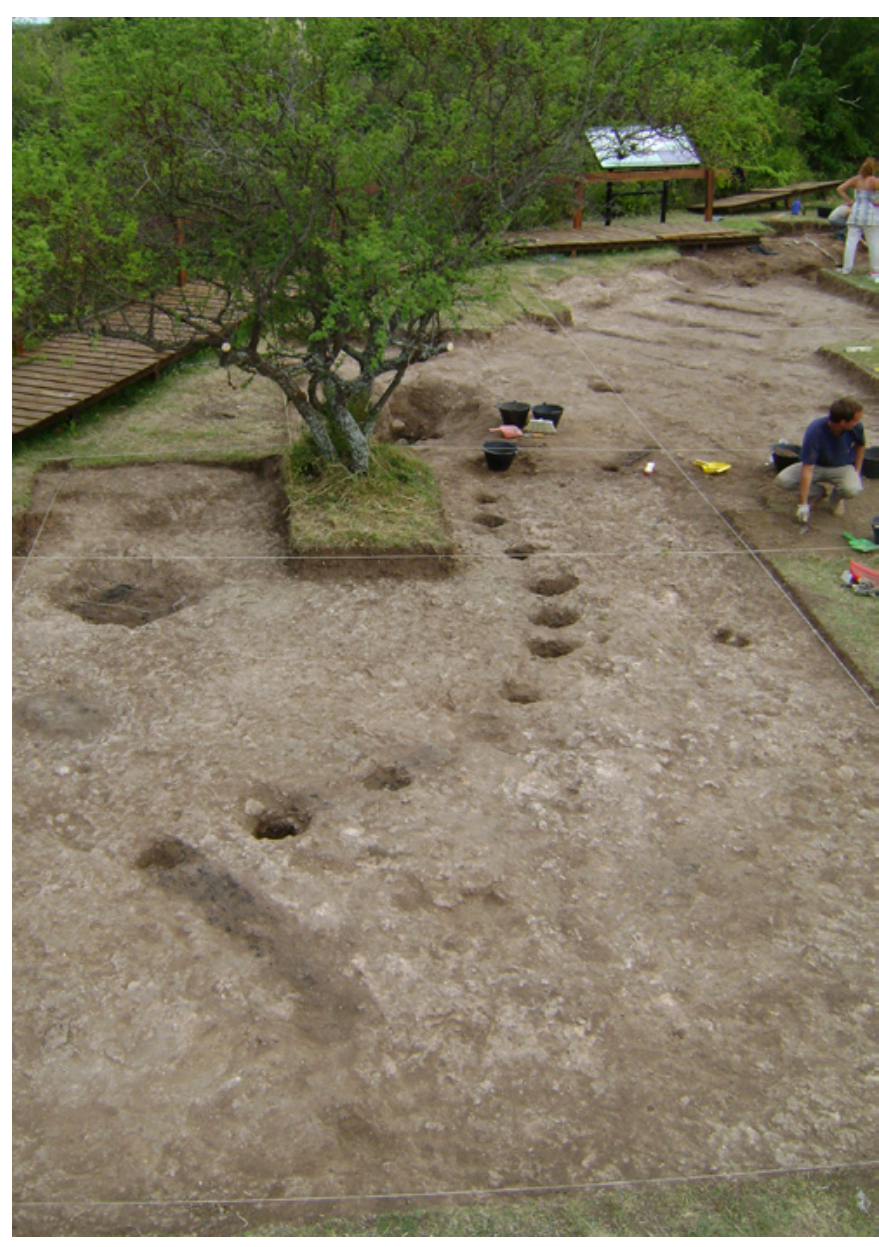

En cuanto al sitio de la batalla, constituye el valor más reconocido del lugar y se encuentra emplazado en las orillas del río Paraná, donde la altura de las barrancas y el meandro del río ofrecieron las condiciones ideales para el emplazamiento de las piezas de artillería que defenderían la soberanía nacional.

Si bien no presenta indicadores monumentales que puedan observarse a simple vista, el lugar posee un rico patrimonio cultural enterrado que se ha ido descubriendo paulatinamente a través de las excavaciones arqueológicas.
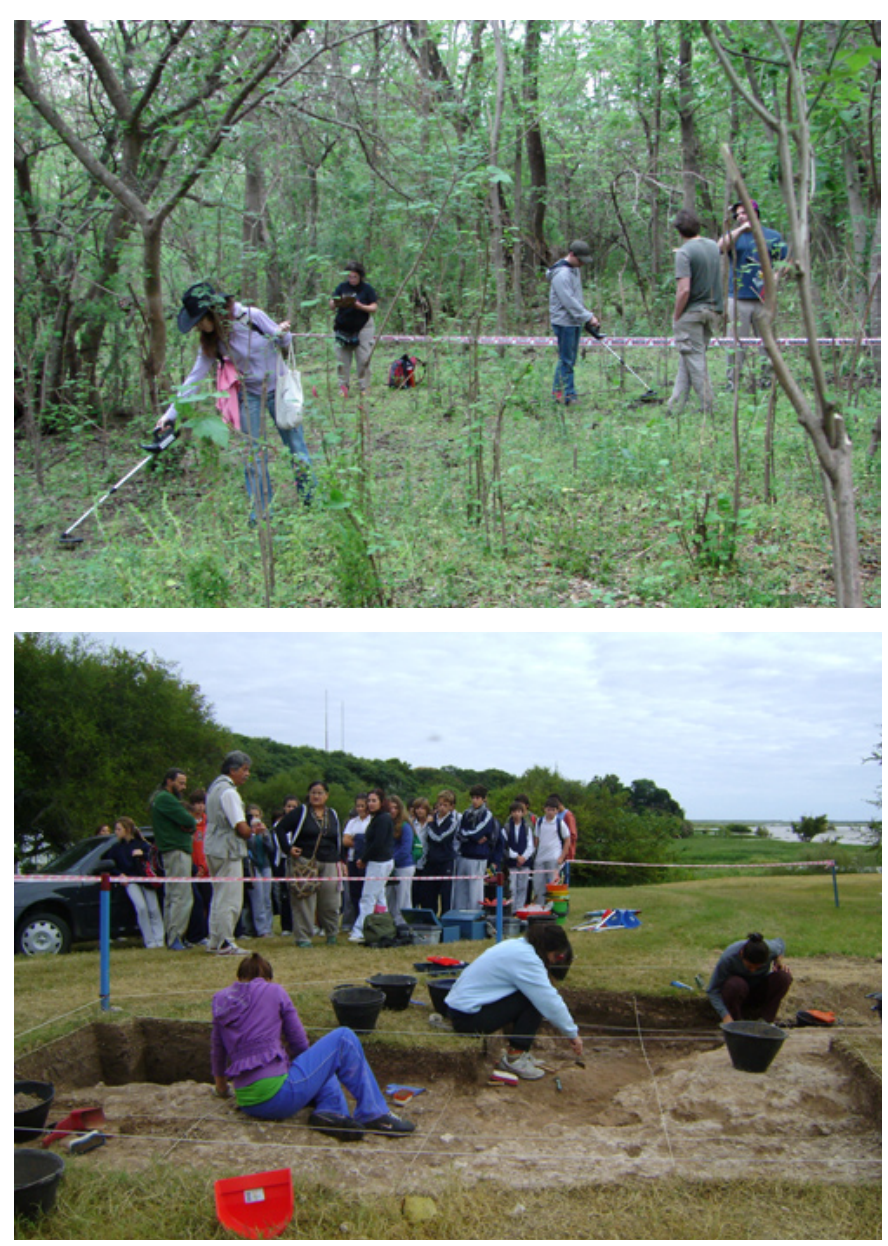

Vista de las excavaciones realizadas en una de las baterías defensivas de Vuelta de Obligado, donde se observa parte de las estructuras para la ubicación de las piezas de artillería | foto Mariano Ramos

Prospección en la zona del bosque en busca del campamento de las tropas argentinas | foto Jimena Clavijo

Un grupo de alumnos de una escuela local y de representantes de los Pueblos Originarios visitando excavación arqueológica

| foto Odlanyer Hernández de Lara

Dentro de las investigaciones que se llevan a cabo en el lugar, que han sido comentadas brevemente en los antecedentes, se halló un plano histórico confeccionado por un capitán inglés que formaba parte de la flota anglo-francesa, donde localizó las baterías defensivas de las fuerzas argentinas, así como el área donde estaría el campamento. Esta información ha contribuido especialmente para la nueva zonificación del sitio. 

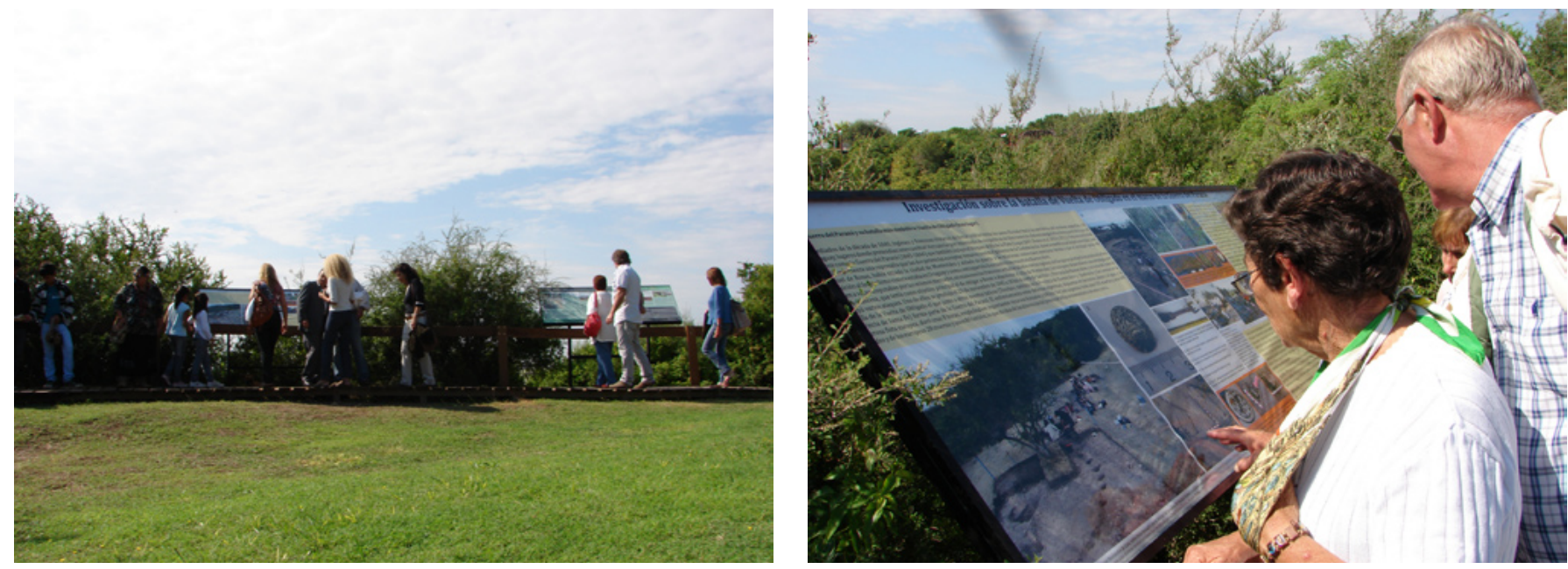

Visita del público al área de la batería General Brown, donde se instaló cartelería relacionada con los recursos paleontológicos y arqueológicos

Detalle del público acercándose al panel con información de la investigación arqueológica que se lleva a cabo en el sitio

| fotos Daniela Storchi Lobos
En algunos de los espacios donde se suponía que estaban las baterías, las excavaciones arqueológicas han hallado evidencias materiales y estructurales que efectivamente dan cuenta de la construcción de espacios fortificados para la defensa y la ubicación de piezas de artillería. Además, la presencia de evidencias de cerámica, metal y madera, datadas hacia mediados del siglo XIX, confirma la asociación del lugar con el hecho histórico.

\section{Sobre los problemas de la conservación}

Las problemáticas de conservación en el sitio Vuelta de Obligado varían según los componentes afectados. Desde el punto de vista del patrimonio natural, la creación de un espacio protegido ha permitido la conservación de un pequeño parche de vegetación donde también se refugian algunas especies animales de importancia para el país o para la región. No obstante, la acción del hombre, a través de la caza, la tala o el avance de la urbanización, ha traído como consecuencia que muchas especies se encuentren en riesgo.

Por otra parte, el patrimonio arqueológico presenta distintos grados de conservación. El sitio de la batalla, por sus dimensiones, ocupa un espacio mucho más extenso que el lugar "protegido" por la creación del parque natural, lo que implica que algunas de las construcciones actuales coincidan con la localización de determinados componentes de la batalla. En este caso se encuentran algunas viviendas de pobladores locales que han sido construidas sobre una de las baterías. Este hecho influye negativamente en la conservación de ese espacio concreto; además, la ubicación sobre la barranca implica que diferentes agentes naturales erosionen el área.

Además, el uso como espacio turístico y de recreación provoca un flujo de visitantes que durante los fines de semana se intensifica. Si bien en el lugar 


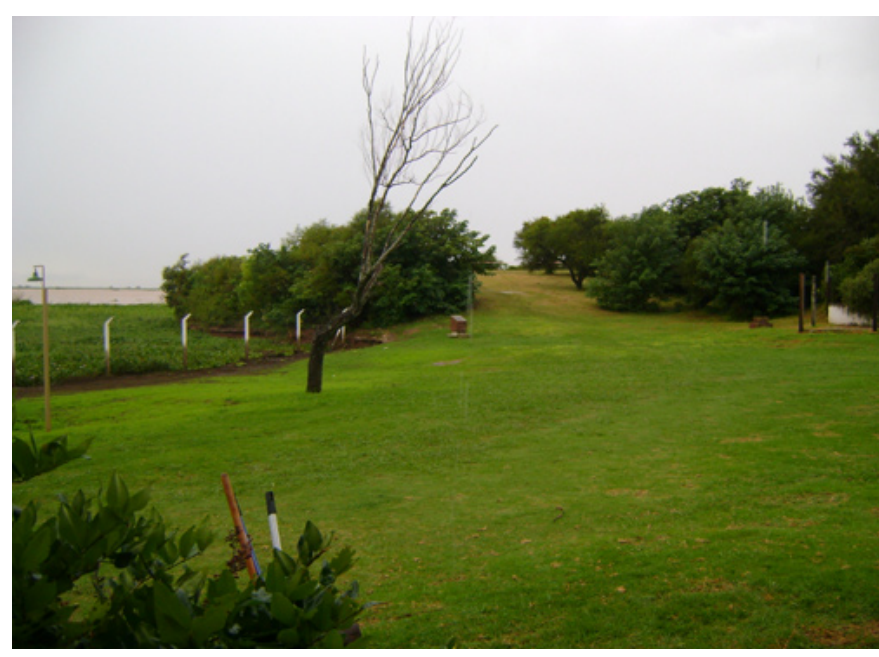

se han creado pasarelas y un camino que encauza al público, del que se pone en duda su integración con el paisaje, la carencia de personal que controle el acceso a los espacios restringidos o no habilitados para la visita, conlleva a que muchas personas circulen libremente por casi todo el predio.

La ausencia de un panel explicativo que regule las actividades permitidas y las restringidas trae como consecuencia que a muchas personas haya que señalarles in situ el impedimento de pescar dentro del lugar o del acceso con animales domésticos y vehículos. Si bien la existencia de cartelería que informe sobre estas cuestiones está prevista en la ordenanza 5333, en la práctica no existe más que un cartel que prohíbe el ingreso con vehículos y la realización de fuegos. Además, la ordenanza referida establece la delimitación de zonas de pesca que no están establecidas.

Uno de los aspectos que están explícitos en la ordenanza antes mencionada es prohibir: "La realización de construcciones, caminos, o cualquier otra obra que implique una modificación del paisaje natural" (ordenanza 5333, hoja 2). Cualquier obra de estas características debe presentar un informe de impacto ambiental y tendrá que ser autorizado por una ordenanza. Esto viene a colación precisamente por la construcción del monumento a la Héroes de la Batalla de Vuelta de Obligado, iniciado por Presidencia de la Nación sin contar con la previa autorización del Concejo Deliberante de San Pedro, violando las normativas existentes. La revisión del proyecto por parte del mencionado Concejo, cuando las obras estaban prácticamente concluidas, conllevó a que expresaran en su dictamen lo siguiente:

"Que esto supone además una grosera desconsideración al rol de este $\mathrm{H}^{\circ}$ Concejo Deliberante y una enorme irresponsabilidad institucional que merecen ser no solo mencionados sino también fuertemente reprochados. La
Comparación del mismo paisaje antes y después de la construcción del camino de cemento e instalación de postes de iluminación

| fotos Odlanyer Hernández de Lara, 2010 (izquierda) y Milva Umaño, 2011 (derecha) 


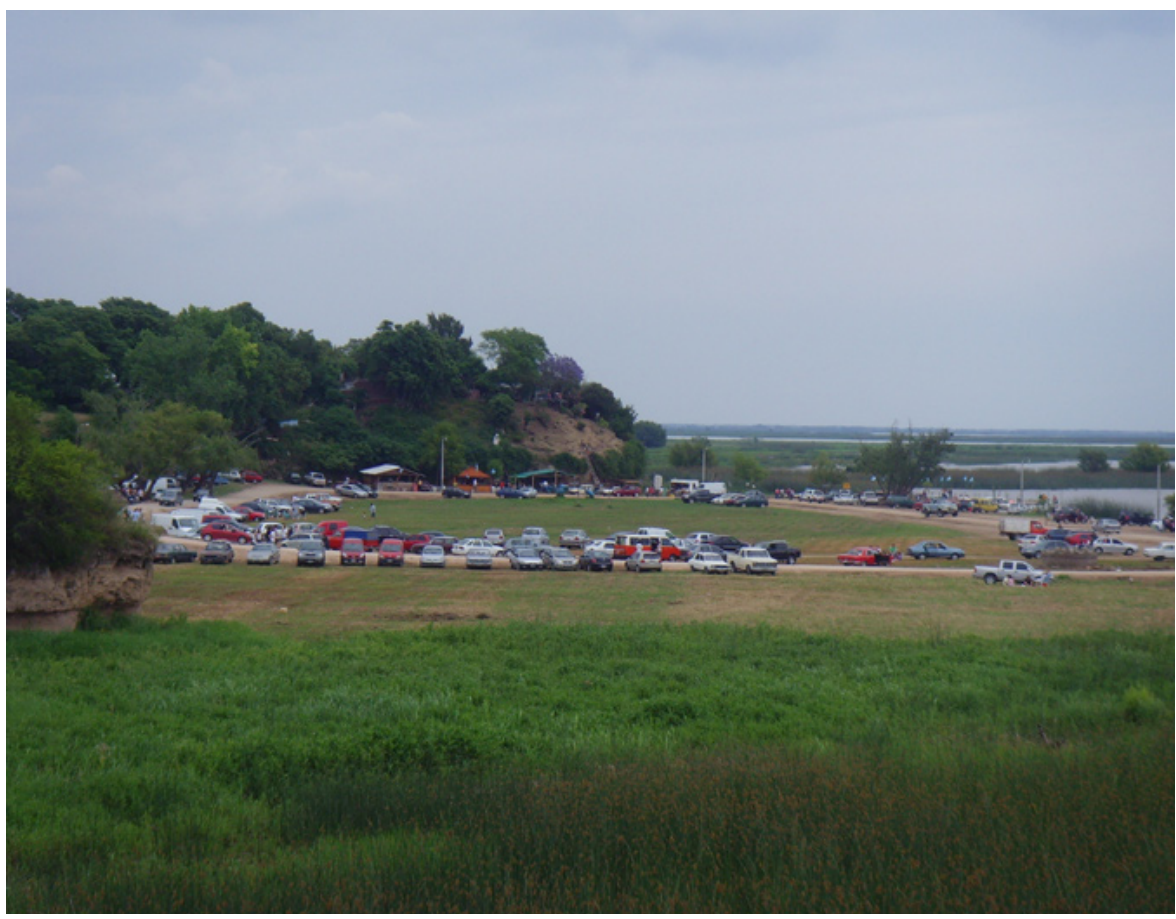

Imagen de la cantidad de vehículos que se estacionan los fines de semana para visitar el área histórica y para el recreo en el río | foto Mariano Ramos

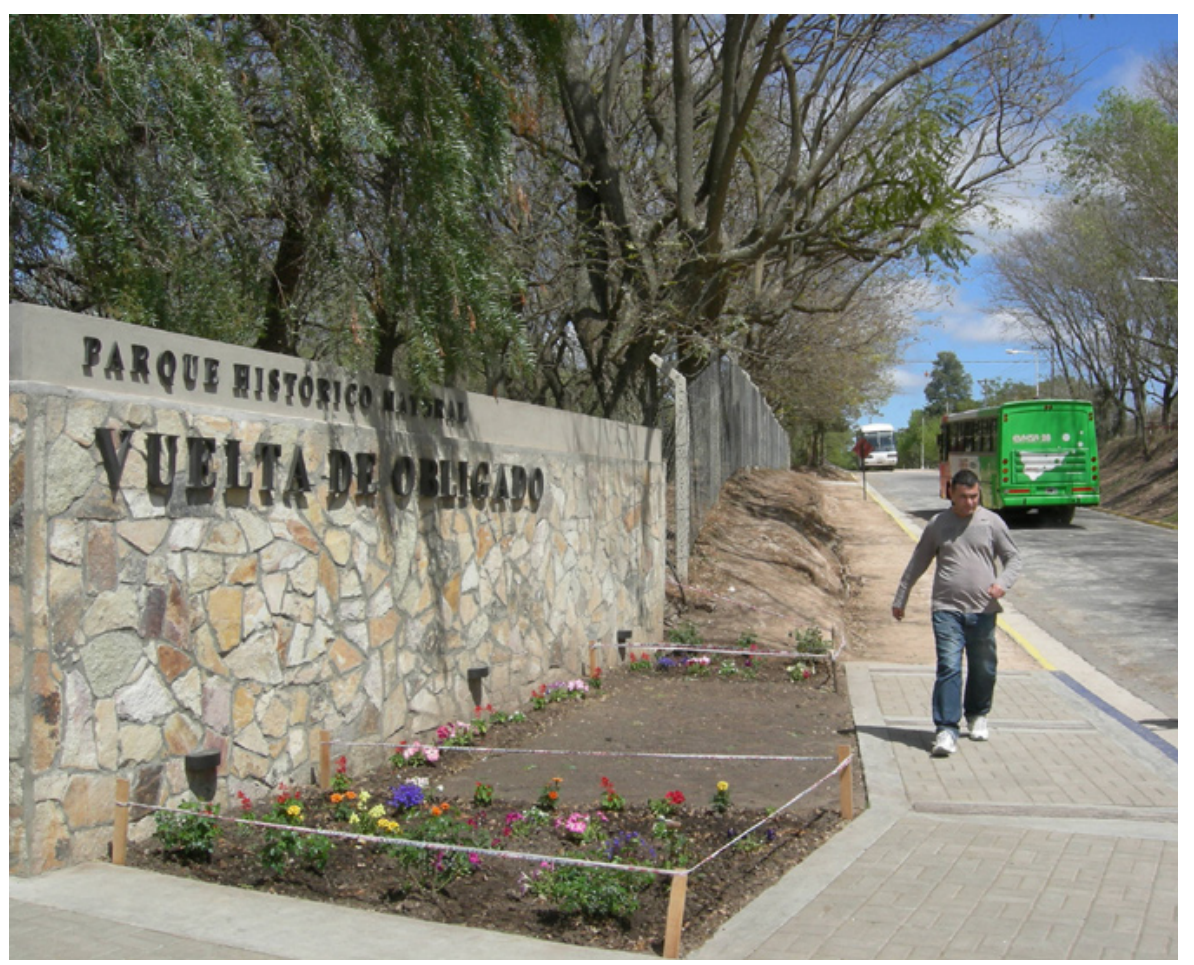

Entrada al Parque Histórico Natural | foto Milva Umaño, 2011 


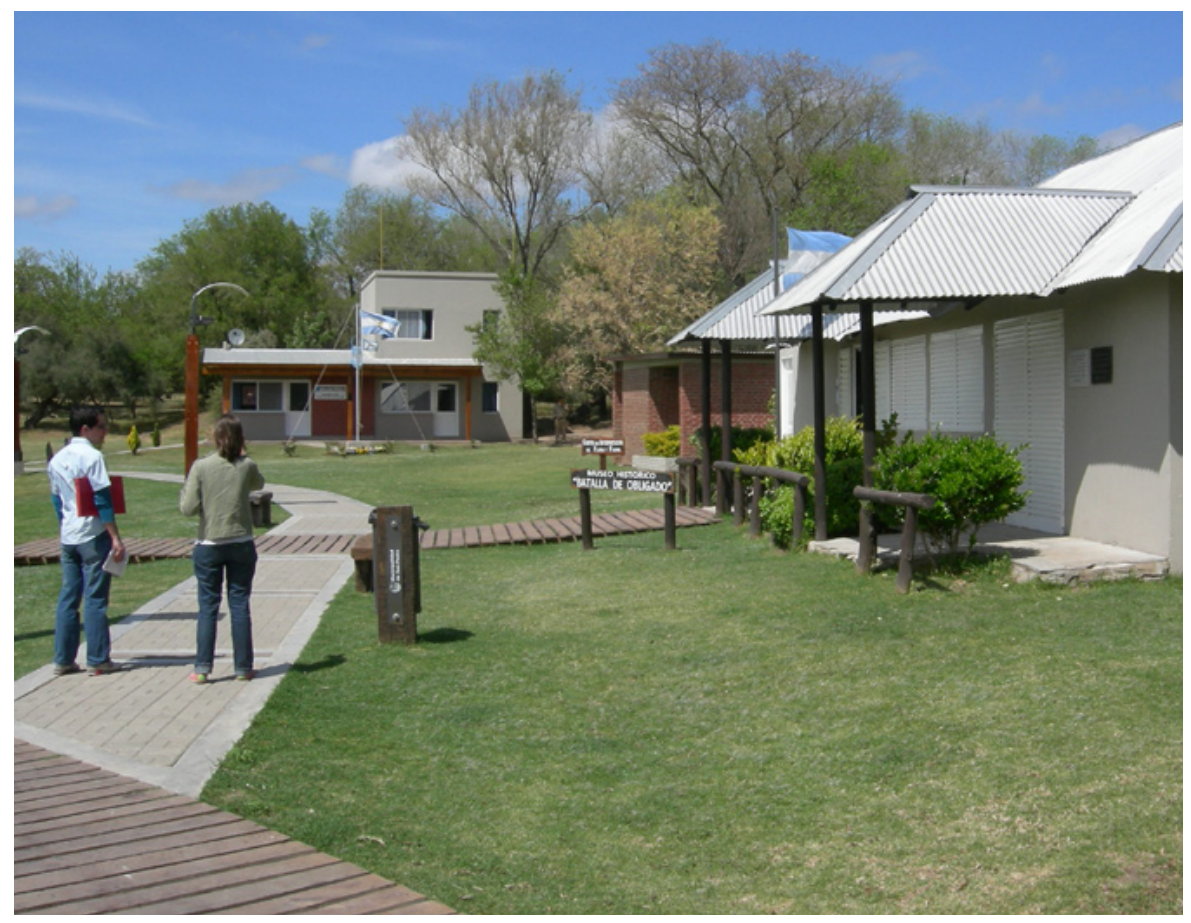

Vista general de las instalaciones del museo y de la guardia de prefectura | foto Milva Umaño, 2011

inexperiencia no da licencia para la transgresión a las normas ni constituye un mérito, menos una virtud. El mayor compromiso no es con las jerarquías en la estructura piramidal del poder sino con la comunidad con la que uno convive a diario" (COMISIÓN, 2010).

Esta opinión, como otras vertidas a lo largo del dictamen mencionado, representa en buena medida lo que piensan muchos pobladores locales respecto a la construcción del monumento, como también se expresara el Centro de Arquitectos de San Pedro, según una comunicación del concejo deliberante (CONCEJO, 2010).

En cuanto a los factores que contribuyen a la conservación, se puede mencionar la creación del parque natural, que ha delimitado un espacio que si bien se puede visitar, se mantienen algunas restricciones que ayudan a la conservación del lugar. Por otra parte, la apropiación de la historia del lugar por algunos de los vecinos y del valor que representa, ha contribuido a la donación de evidencias arqueológicas de la batalla al museo de sitio, así como al cuidado del lugar.

\section{Dinámica socio-territorial}

El pueblo de Vuelta de Obligado está compuesto en su gran mayoría por familias de pescadores que viven de los recursos que les brinda el río Paraná. 


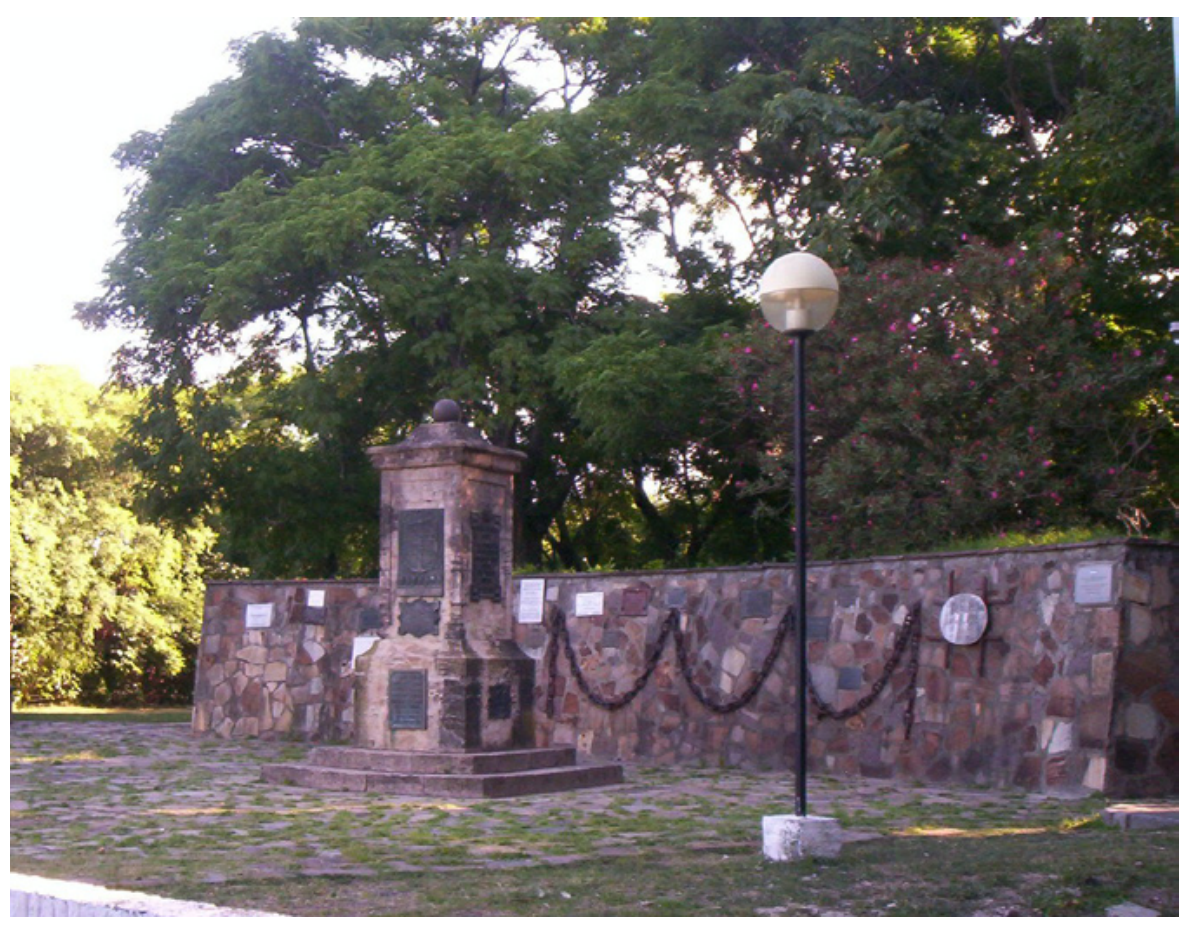

Vista del antiguo monumento donde se observa el monolito y gran cantidad de placas colocadas por diversos sectores en homenaje de la batalla | foto Mariano Ramos

En los últimos años, la valorización del lugar como espacio de recreo, fundamentalmente para los vecinos de la cercana ciudad de San Pedro, conllevó a la creación de un camping y la dedicación de varios pobladores locales al alquiler de lanchas que hacen recorridos por el río o trasladan a pescadores hasta las islas cercanas, así como a la venta de comidas y artesanías.

La afluencia de turismo, en parte por la riqueza natural del paraje, pero fundamentalmente por la resignificación del lugar como espacio histórico relevante para la nación argentina, ha conllevado la venta de productos de producción casera (mermeladas, dulces, panes, licores, etc.) por parte de algunos vecinos. La venta de pescado también ha proliferado en alguna medida, así como el alquiler de cabañas para fines de semana. Además, durante los fines de semana, cuando llega al lugar un mayor monto de visitantes, vecinos de San Pedro también se acercan con diversos productos para la venta en las banquinas de la calle principal del pueblo. Por otra parte, la delimitación del área protegida y el museo han creado algunas plazas de trabajo, aunque muy limitadas. Una de las problemáticas de mayor impacto en la localidad tiene que ver con la propiedad de la tierra, ya que una parte importante de las casas de pescadores, especialmente de las familias que más tiempo llevan viviendo en el paraje son concesiones de la municipalidad. La significación de Vuelta de Obligado en los últimos años ha traído varios conflictos en este sentido, por el potencial desalojo del lugar. 


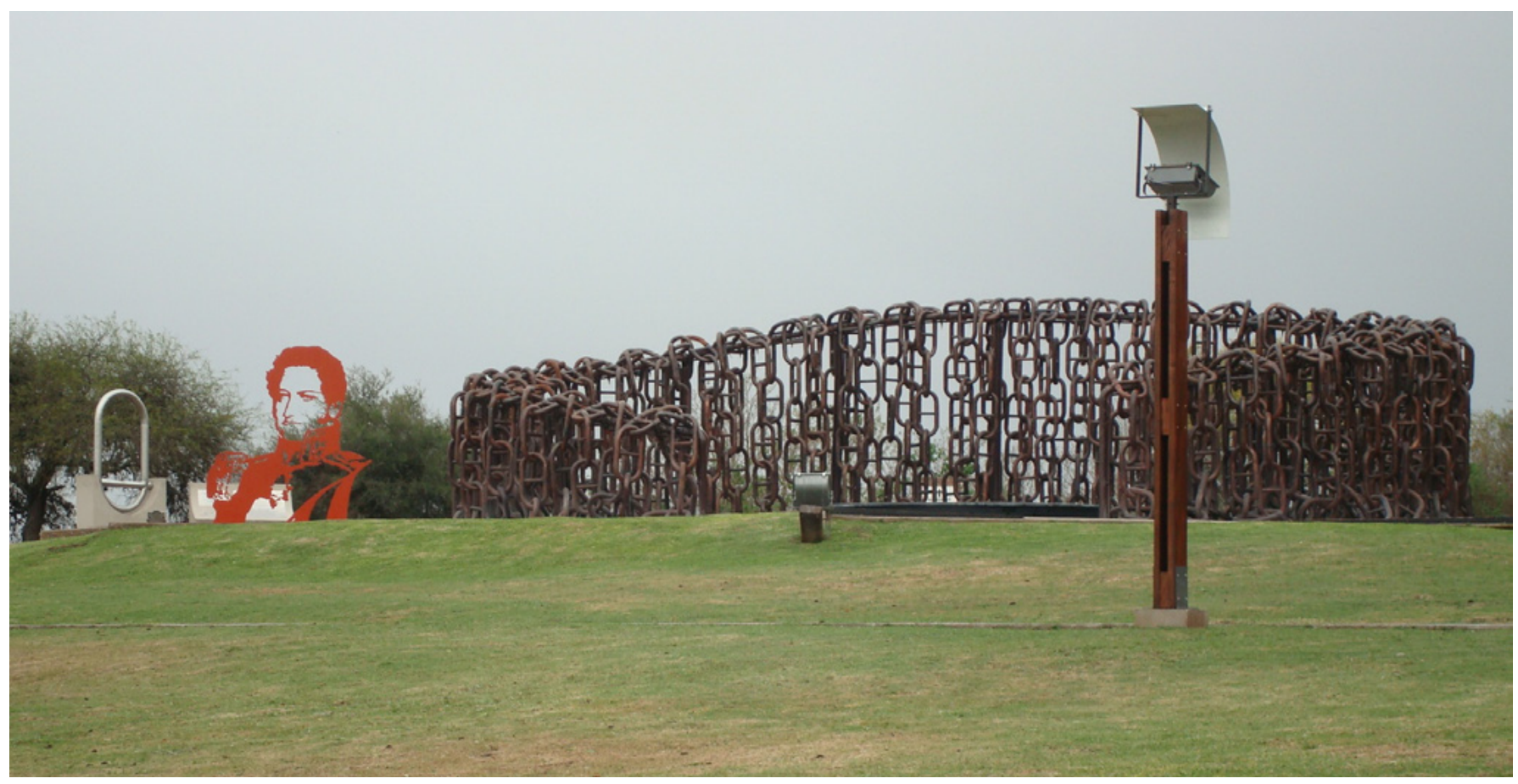

Vista del nuevo monumento inaugurado en el año 2010, ocasión en la que se declara el día de la batalla (20 de noviembre) como día de la Soberanía Nacional | foto Matilde Lanza, 2011

En sentido general, estas actividades han mejorado, en alguna medida, la calidad de vida de los pobladores locales, lo que puede llegar a intensificarse con políticas de manejo adecuadas para el área.

\section{ABORDAJE DE LA PROBLEMÁTICA}

Sin lugar a dudas, a partir del año 2010, el sitio histórico de la batalla de Vuelta de Obligado ha alcanzado una nueva connotación con el reconocimiento nacional del lugar para representar el día de la soberanía nacional. Si bien ello implicó la construcción de un monumento que no cumplió con los requisitos del área protegida -como lo remarcó el Concejo Deliberante de San Pedro (COMISIÓN, 2010)-, también hay que destacar que sirvió para que el lugar despertara nuevamente el interés de los políticos de turno.

No obstante, es preciso señalar que, a pesar de las diversas ordenanzas promulgadas y la participación de la municipalidad de San Pedro en el manejo del área protegida, así como del trabajo arqueológico que se viene realizando por un equipo de investigación desde hace más de diez años, las autoridades no parecen tener un conocimiento profundo del valor de esta localidad. Esto puede observarse con la reciente denuncia del Instituto Nacional de Antropología y Pensamiento Latinoamericano (INAPL) al secretario de cul- 
tura de San Pedro, José Luis Aguilar, por sus exploraciones ilegales en la zona de la batalla (DENUNCIA, 2012).

Uno de los principales objetivos de esta nueva propuesta ha sido precisamente establecer los valores del área, para poder avanzar en una apropiada puesta en valor del bien, considerándolo en todos sus aspectos, tanto culturales como naturales. Es a partir del conocimiento de los valores del bien que se puede profundizar en el estudio de los recursos de la localidad, lo que permitirá brindar soluciones concretas a los problemas que le afectan.

\section{Aspectos sobre el manejo de los recursos afectados}

Teniendo en cuenta lo planteado, respecto al patrimonio natural de la localidad de Vuelta de Obligado, y considerando que las principales actividades que impactan el medio ambiente lo constituyen la caza, la tala y el avance de la urbanización, es importante destacar que estas acciones forman parte del modo de vida de los habitantes locales (caza y tala), por lo que no deben prohibirse en su totalidad. Un monitoreo sistemático del estado de conservación del medio ambiente del lugar, así como la reforestación de especies nativas contribuiría efectivamente a un equilibrio entre naturaleza y pobladores locales, en pos del desarrollo de ambos.

En cuanto al avance de la urbanización, es de significativa importancia establecer regulaciones urbanas que establezcan las características de las edificaciones del lugar, para mantener la armonía constructiva. Además, el potencial arqueológico y natural del área justifica la realización de estudios de impacto ambiental y arqueológico para evaluar y rescatar el patrimonio de la localidad previo a su destrucción. Un ejemplo de ello es la construcción de una vivienda sobre una de las baterías de la batalla, donde deberían realizarse excavaciones de rescate, para intentar recuperar los remanentes que pueden existir, previo acuerdo con el vecino.

Por otra parte, el desarrollo turístico en los últimos años ha generado un importante monto de visitantes, que en ocasiones superan las capacidades de manejo del área, ya que en la actualidad existe sólo una persona que se ocupa de regular la entrada y hacer cumplir las limitaciones del parque. Ello implica que el público circule libremente por espacios no permitidos y se genere un impacto a la flora del lugar que puede ser controlado. Para esto no solamente es necesario el incremento del personal en el parque, sino también su formación para la gestión del patrimonio natural y cultural presente en el área.

Además, la existencia de paneles explicativos dentro del área protegida es mínima, lo que contribuye a la desinformación de la población y, por lo tanto, al incumplimiento de las limitaciones establecidas. Es imprescindible 
la incorporación de paneles que regulen las actividades permitidas y las restringidas. El incremento del turismo genera un caudal de visitantes que debe controlarse, estableciendo la cantidad de visitantes diarios permitidos, para evitar futuros impactos negativos. Para ello es fundamental la zonificación del espacio, que puede diferenciar áreas de uso extensivo y áreas de uso restringido. Además, a nivel general, se debe mejorar la cartelería del sitio que, en algunos casos, existe pero no es suficiente para la explicación de los diferentes espacios visitados. Es escasa la referencia a los trabajos arqueológicos en cada lugar, así como la identificación y explicación in situ de la biodiversidad.

Un aspecto que se debe considerar es el establecimiento de la dificultad de los recorridos dentro del área, teniendo en cuenta la presencia de personas con movilidad reducida. Esta información no solamente debe estar explícita en el parque, sino también en los folletos de divulgación de este espacio.

En cuanto a la protección del lugar, es preciso mencionar que el acondicionamiento del espacio realizado en 2010 implicó la construcción de pasarelas con barandas que protegen al público en el área de las barrancas. No obstante, consideramos que este mismo sistema debería implementarse para la delimitación interna del espacio, limitando los lugares visitables y los intangibles.

La importancia de una política de manejo de los recursos tanto naturales como culturales en el parque debe considerarse en función de lo propuesto por la Administración de Parques Nacionales (ADMINISTRACIÓN, 2001), donde se establecen como aspectos básicos: inventario de recursos, evaluación de los recursos, consideración del valor histórico y social y monitoreo. Esto contribuye a un mayor control de los recursos existentes en el área protegida y a su mejor conservación, llevándose a cabo en diversas etapas que puedan contemplar la totalidad de los recursos: "Esta estructura asegura que los recursos valorizados por su carácter histórico, potencial científico y demás valores involucrados, sean reconocidos, identificados, comunicados, evaluados y considerados para el manejo" (ADMINISTRACIÓN, 2001: 4).

Por otra parte, es importante la creación de un nuevo plan de manejo que tenga en cuenta todos los aspectos antes mencionados, donde se trabaje basándose en los valores establecidos en el área. Su constante actualización y retroalimentación de los resultados alcanzados contribuirá significativamente a un mejoramiento exponencial del manejo. Para ello resulta de gran importancia la realización de encuentros con la comunidad para describir y ampliar el valor de ese espacio, haciéndola partícipe de la construcción del conocimiento y la implementación del nuevo plan de manejo en conjunto con los demás sectores involucrados. Además, es trascendental que se comuniquen a la sociedad los avances de investigación que se llevan a cabo en el lugar, tanto desde el punto de vista arqueológico, como paleonto- 
Agradecimientos

Este trabajo es el resultado del Seminario "Gestión del Patrimonio Cultural: una mirada desde la práctica", impartido por Roberto Molinari, en la Facultad de Filosofía y Letras de la Universidad de Buenos Aires. Agradecemos sobremanera sus correcciones y oportunas observaciones para mejorarlo. También tenemos que resaltar la ayuda del Dr. Mariano Ramos, director del Programa de Arqueología Histórica y Estudios Pluridisciplinarios de la Universidad Nacional de Luján, por su constante apoyo y permitir la participación en las excavaciones arqueológicas en Vuelta de Obligado. lógico y ambiental, en charlas informativas o seminarios que involucren a los protagonistas de las investigaciones y a la comunidad, contribuyendo así a una mayor apropiación del patrimonio local.

En otro orden de cosas, todas las modificaciones propuestas implican una nueva planificación del área en cuestión, lo que contribuirá no solamente a la actualización de las circunstancias, sino también a una efectiva puesta en práctica de los planes de manejo y la creación de programas que abarquen la protección y recuperación, la investigación y monitoreo, el uso sustentable, la interpretación, la educación ambiental y la difusión, etc.

Uno de los aspectos importantes en el plan de manejo es la zonificación del espacio, lo que ha sido tratado en la propuesta anterior (BODRATI; BODRATI; CUENCA et ál., 2005) que, como se ha visto, es aplicado parcialmente. En cuanto a la zonificación, lamentablemente, la distribución de distintos usos del paisaje no ha sido respetada hasta el momento, lo que impacta directamente en la conservación de los recursos, tanto culturales como naturales. En este caso proponemos un incremento del área de amortiguamiento, justificado por la presencia de recursos culturales que no habían sido tenidos en cuenta en la propuesta anterior.

Teniendo en cuenta todo lo anterior, y considerando que los cambios propuestos necesitan de un marco legal pertinente para su implementación, sugerimos la emisión de una nueva ley u ordenanza que modifique la categoría de parque histórico natural por paisaje cultural evolutivo vivo, lo que implica un cambio conceptual e instrumental del espacio que permitirá aplicar nuevas políticas de manejos que ayudarán a la conservación y protección de este paraje. Esto conlleva además a una potencial integración regional con otras localidades a lo largo del Paraná que permitirá crear corredores naturales e históricos, especialmente vinculantes a través del rico patrimonio natural y cultural de la región. Para ello creemos de fundamental importancia la inclusión y participación activa de los pobladores locales entendidos como actores centrales en la protección patrimonial, en aras de crear ambientes donde la comunidad sea protagonista de su propio entorno. 


\section{BIBLIOGRAFÍA}

- ADMINISTRACIÓN de parques nacionales (2001) Reglamento para la Conservación del Patrimonio Cultural en Jurisdicción de la APN y Política de Manejo de Recursos Culturales, Resolución 115/2001. Buenos Aires: Administración de Parques Nacionales. Documento interno <http://www.nahuelhuapi.gov.ar/normativas/manejo/REGL AMENTO\%20PARA\%20LA\%20CONSERVACION\%20DE L\%20patrimonio\%20cultural.pdf>

- BODRATI, A.; BODRATI, G.; CUENCA, L. et ál. (2005) Propuesta de lineamientos para el Plan de Manejo de la Reserva Municipal Vuelta de Obligado (San Pedro, Buenos Aires, Argentina). Buenos Aires: Aves Argentinas I Asociación Ornitológica del Plata, 2005 <http://www. infoguiasanpedro.com/download/Plan_de_manejo_ Vuelta_de_Obligado.pdf> [consulta: 03/02/2014]

- COMISIón de planeamiento, ocupación del suelo y obras (2010) Dictamen sobre el Expediente N. ${ }^{\circ}$ 2122/10. Municipalidad de San Pedro. En: Proyecto de Ordenanza autorizando el emplazamiento de la obra conmemorativa a la batalla de Obligado en la reserva natural histórica y refugio vida silvestre municipal. Expediente N.$^{0}$ 4107-6496/10 (Fs. 01/445) [en línea] <http://www.hcdsanpedro.gov.ar/detalle expediente. php?id=4456> [consulta: 05/02/2014]

- CONCEJo deliberante de San Pedro (2003) Ordenanza No. 5333. Declarando reserva natural, historica y refugio de vida silvestre a los bosques nativos sitos en la Circunscripción VIII, Sección R, Parcela 1031 cb, del Paraje de Vta. de Obligado [en línea], junio 27 de 2003. <http://www.hcdsanpedro.gov.ar/detalle_ordenanza. php?id=2209> [consultado: 05/02/2014]

- DLAPA, E. (2011) Descubren asombroso sitio arqueológico en la puerta del Parque Natural Vuelta de Obligado. San Pedro Informa [en línea], martes 06 de septiembre de 2011, <http://www.sanpedroinforma. com.ar/index. php?option=com k2\&view=item\&id=7334: descubren-asombroso-sitio-arqueol\%C3\%B3gico-en-lapuerta-del-parque-natural-vuelta-de-obligado> [consulta: 20/10/2011]

- DENUNCIA y polémica por los objetos históricos de Obligado. La Opinión Semanario [en línea], 18 de abril de 2012, <http://www.laopinionsemanario.com.ar/ noticia/denuncia-y-pol-mica-por-los-objetos-hist-ricos-deobligado-221711352934681> [consulta: 03/02/2014]

- LANZA, M.; HERNÁNDEZ DE LARA, O. ; RAMOS, M. et ál. (2011) En busca del campamento de la batalla de Vuelta de Obligado: técnicas y metodologías de prospección. En RAMOS, M. et ál. (eds.) Arqueometría argentina: estudios pluridisciplinarios. Buenos Aires: Aspha, 2013, pp. 27-36

- RAMOS, M.; BOGNANNI, F.; LANZA, M. et ál. (2011) Arqueología histórica de la batalla de Vuelta de Obligado, provincia de Buenos Aires, Argentina. En RAMOS, M.; HERNÁNDEZ DE LARA, O. (eds.) Arqueología histórica en América Latina. Perspectivas desde Argentina y Cuba. Buenos Aires: Programa de Arqueología Histórica y Estudios Pluridisciplinarios, UNLu, 2011, pp. 13-32

- SALERNO, V. (2011) Trabajo arqueológico y representaciones del pasado prehispánico en Chascomús. Tesis doctoral inédita, Universidad de Buenos Aires,2011

- SIERRA, E. A. (2005) Reserva Municipal y Refugio de Vida Silvestre. infoguíasanpedro.com [en línea] <http://www.infoguiasanpedro.com/sanpedro/geografial reservaobligado.asp> [consulta: 23/10/2011] 